(2) Open Access Full Text Article

REVIEW

\title{
Development of hypertension - clinical impact of dysregulation of circadian rhythms and implications for treatment
}

This article was published in the following Dove Press journal:

ChronoPhysiology and Therapy

26 June 2015

Number of times this article has been viewed

\author{
Kristen Solocinski ${ }^{1,2}$ \\ Michelle L Gumz ${ }^{1,2}$ \\ 'Department of Medicine, \\ ${ }^{2}$ Department of Biochemistry and \\ Molecular Biology, University of \\ Florida, Gainesville, FL, USA
}

\begin{abstract}
Blood pressure, like most physiological processes, exhibits a circadian pattern of variation. Disruption of the normal circadian rhythm of blood pressure is associated with end organ damage and increased risk of adverse cardiovascular outcomes. In this review, we discuss the role of the renin angiotensin aldosterone system and the molecular clock in maintaining circadian blood pressure patterns. We also consider disrupted circadian blood pressure rhythms and hypertension in distinct populations and the role of chronotherapy in the treatment of hypertension.
\end{abstract}

Keywords: clock, kidney, adrenal, aldosterone, chronotherapy, sleep

\section{Introduction}

Since the formation of earth, the sun has risen and set with a predictable rhythmicity giving the world day and night. This daily, circadian rhythm has been adapted by life in the form of rhythmic expression of genes and behaviors around a $\sim 24$ hour day. Indeed, life forms from archaebacteria to humans exhibit circadian rhythms in physiological function. ${ }^{1}$ On a molecular level, circadian rhythms are orchestrated by a complex network of transcription factors and associated regulatory proteins that control gene expression and protein function, resulting in circadian rhythms in most physiological processes. $^{2}$

The molecular clock consists of a transcription/translation feedback loop. In the positive arm, the circadian clock proteins Bmall and CLOCK heterodimerize to bind E-box response elements in the promoters of target genes. These target genes include Per and Cry, which encode the Per and Cry proteins. In the negative arm of the feedback loop, Per and Cry antagonize the action of Bmal1/CLOCK, thereby inhibiting their own transcription. Bmal1/CLOCK also activate the nuclear orphan receptor genes Ror and Nrld1, encoding ROR $\alpha$ and Rev-erb $\alpha$. These receptors in turn mediate opposing action on expression of the Bmall (Arntl1) gene. This clockdependent transcriptional mechanism regulates expression of a significant number of circadian target genes. Indeed, a recent landmark study in mice demonstrated that nearly $50 \%$ of expressed genes are regulated by this clock mechanism in a tissuespecific manner. ${ }^{3}$ This transcriptional mechanism is thought to underlie the known circadian variations in physiological functions, such as blood pressure. The molecular clock functions in nearly every cell and tissue type. Moreover, post-transcriptional and post-translational regulatory events also contribute to the mechanism of the circadian clock. ${ }^{4}$
Correspondence: Michelle L Gumz Department of Medicine, Division of Nephrology, Hypertension and Renal Transplantation, University of Florida, 1600 SW Archer Road Box 100224

Gainesville, FL 32610, USA

$\mathrm{Tel}+\mathrm{I} 3522736887$

Fax + I 3523925465

Email michelle.gumz@medicine.ufl.edu 
Blood pressure exhibits a circadian rhythm, with a rise during the active period and a "dip" or decrease of about $10 \%-20 \%$ during the rest period. Individuals who do not exhibit this circadian rhythm of blood pressure are termed "non-dippers" and are known to be at increased risk for target organ damage and adverse cardiovascular outcomes. ${ }^{5}$ The prevalence of non-dipping varies between patient populations but is estimated to occur in approximately $50 \%$ of hypertensives and more than $80 \%$ in at risk hypertensives such as those with chronic kidney disease (CKD) and saltsensitive hypertensives. ${ }^{6}$ Indeed, non-dipping is recognized as a risk factor for cardiovascular disease (CVD) and endstage renal disease (ESRD). ${ }^{7}$ While normotensive people experience a non-dipping prevalence of about $6 \%,{ }^{8}$ in one group of hypertensive patients taking three anti-hypertensive medications, $86 \%$ of patients exhibited the non-dipping pattern. ${ }^{9}$ Interestingly, it was reported that taking one medication at bedtime (as opposed to in the morning) decreased nondipping prevalence from $84 \%$ to $43 \%{ }^{9}$ There have also been reports that suggest ethnicity plays a role in dipping status, providing evidence that Hispanics and African Americans are more likely to be non-dippers than Caucasians. ${ }^{10,11}$ Below, we discuss the role of the renin angiotensin aldosterone system (RAAS) and the molecular clock in maintaining circadian blood pressure patterns. We also consider non-dipping status and hypertension in distinct populations and the role of chronotherapy in the treatment of hypertension.

\section{The RAAS}

All forms of Mendelian (inherited) hypertension are linked to a defect in the RAAS. Briefly, when low blood pressure is sensed, the juxtaglomerular cells release the enzyme renin. In the blood stream, renin converts angiotensinogen to AngI which is then converted to AngII by ACE. AngII is itself a vasoconstrictor which causes an increase in blood pressure due to decreased volume for blood to occupy. AngII also stimulates aldosterone secretion which results in increased sodium reabsorption by the kidney and a consequent increase in blood pressure. There is increasing evidence for an intrarenal RAAS system as well as a whole-body system. ${ }^{12}$

Hypertension is the major risk factor for CVD which is the leading cause of death in America. ${ }^{13}$ It is also a major risk factor for developing ESRD. ${ }^{14}$ Thus, there is a need to better control hypertension. This is attempted through the use of therapeutics which target several components of the RAAS pathway. ACE inhibitors, direct renin inhibitors and angiotensin receptor blockers (ARBs) are commonly used treatments for hypertension. Combination therapy using a direct renin inhibitor (aliskiren) plus an ARB (valsartan) was more effective at lowering blood pressure than either treatment alone. ${ }^{15}$ Further exploration into this combination therapy indicated that the change in blood pressure due to treatment was more pronounced in non-dipper patients, patients who do not experience the normal "dip" in blood pressure values during the rest period, suggesting a more potent inhibition of the RAAS in the non-dipper population. ${ }^{16}$

In addition to an endocrine and renal RAAS, there is a brain RAAS as well, isolated by the blood-brain barrier. The brain RAAS has been implicated in hypertension in animal models. ${ }^{17,18}$ Campos et al developed a transgenic rat with angiotensinogen levels reduced specifically in the brain to a level about $10 \%$ of that of a normal rat. ${ }^{19}$ These rats have decreased blood pressure as a result of the altered brain RAAS. Baltatu et al tested the role of the brain RAAS in a model of renal hypertension mimicked by subcutaneous AngII infusion. Strikingly, the hypertensive phenotype was attenuated in the rats with reduced brain angiotensinogen, ${ }^{20}$ indicating the important role of brain RAAS in systemic blood pressure regulation. Furthermore, subcutaneous AngII infusion is a reproducible model for non-dipping hypertension, inducing a shift in the circadian rhythm of blood pressure. ${ }^{21}$ The reduced brain angiotensinogen rats also have decreased plasma renin activity levels when stressed compared to control rats. ${ }^{22}$ This implies that the brain RAAS has some effect on the intrarenal RAAS.

Renin, AngII, and aldosterone exhibit similar circadian rhythms of release, peaking in early morning hours. ${ }^{23}$ Jensen and Pedersen showed that there is an inverse correlation between plasma renin activity and blood pressure dipping magnitude at night. ${ }^{24}$ Higher levels of plasma renin activity lead to a smaller dip in night time blood pressure.

\section{Role of the molecular clock in circadian blood pressure patterns: evidence from animal models}

Maintaining a normal circadian blood pressure rhythm is associated with improved cardiovascular outcomes. ${ }^{6}$ For an in depth review of the mechanism of circadian rhythms, see Richards and Gumz. ${ }^{1}$ The basic mechanism of the molecular clock involves transcriptional regulation of target gene expression. Blood pressure studies performed in knockout mouse models lacking one or more of the core clock genes have demonstrated an important role for several clock proteins in blood pressure regulation. ${ }^{25}$

A possible mechanism contributing to hypertension was observed in Cry1/Cry2 knockout (KO) mice. ${ }^{26}$ These mice 
lacking integral circadian clock genes have salt-sensitive hypertension and increased plasma aldosterone. Microarray analysis identified an enzyme in the aldosterone synthesis pathway (Hsd3b6) as having increased expression in these mice. This enzyme is involved in the conversion of pregnenolone to progesterone which is an early step in aldosterone synthesis, and its expression is restricted specifically to zona glomerulosa cells of the adrenal gland. This enzyme could be a possible target to treat hypertension.

Sueta et al recently investigated the effects of two different ARBs (olmesartan and valsartan) on spontaneously hypertensive rats. ${ }^{27}$ Since different ARBs have different affinities for the AngII receptor ( $\left.\mathrm{AT}_{1} \mathrm{R}\right)$, the goal of the experiments was to see if different binding affinity could account for different effects of treatment in aged rats. They found that olmesartan lowered blood pressure for significantly longer than valsartan, possibly due to the higher binding affinity of olmesartan for $\mathrm{AT}_{1} \mathrm{R}$ than valsartan. ${ }^{28,29}$ By comparing young and aged Wistar-Kyoto rats (the normotensive control rat), this study found that increased age, not hypertension alone, was probably responsible for abnormalities related to aging including vascular endothelial dysfunction, blood pressure variability, and impaired autonomic function. However, comparison of aged WKY rats and spontaneously hypertensive rats demonstrated that hypertension increased the magnitude of these dysfunctions in aged rats.

Another animal model that has been useful in hypertension research is the Dahl S rat. These rats are sensitive to dietary salt intake which can cause large increases in blood pressure. One of the major points of dysfunction in these rats is the outer medulla of the kidney. ${ }^{30}$ These rats have a phenotype similar to that of many African Americans, about 50\%-75\% with hypertension are salt sensitive. ${ }^{31}$ An extensive genetic analysis by Cowley et al aimed to identify genes responsible for the salt sensitivity observed in these rats. ${ }^{32}$ Of a number of candidate genes, $R f w d 2$ (also called COP1) stands out. It is an E3 ubiquitin ligase which regulates FoxO1-mediated gene expression and is a tumor suppressor. While $R f w d 2$ has not been linked to any cardiovascular functions, Cowley et al showed that it interacts with many genes related to circadian rhythms. Some correlated genes include Clock and Csnkld which phosphorylates Per proteins to allow their translocation into the nucleus. ${ }^{33} R f w d 2$ has also been shown to be involved in the stabilization of Per2 through its E3 ubiquitin ligase activity. ${ }^{34}$

The suprachiasmatic nucleus ( $\mathrm{SCN}$ ) in the brain is entrained by light and helps set the cycle of circadian rhythms and synchronize peripheral tissue clocks. ${ }^{35}$ It is already clear that disruptions in circadian rhythms and proteins can lead to hypertension so it follows that SCN impairment might also lead to changes in ability to control blood pressure. Changes in neurotransmitter levels in the SCN of hypertensive animals ${ }^{36}$ and humans ${ }^{37}$ have been noted but it is unclear whether these changes are the cause or an effect of hypertension.

Buijs et al investigated the involvement of the $\mathrm{SCN}$ in blood pressure regulation by creating lesions in the SCN in mice. ${ }^{38}$ Mice with lesions were unable to deal with a saline injection leading to an increase in blood volume and pressure, unlike normal control mice which did not show a hypertensive response to the injection. The authors also found that another part of the brain, the nucleus tractus solitarius (NTS), has neuronal projections contacting and communicating with the SCN. They found evidence that the NTS communicates blood pressure information back to the SCN and creating a lesion in the NTS leads to decreased $\mathrm{SCN}$ activity but no change in blood pressure levels compared to controls.

Using sino-aortic denervated (SAD) male Sprague-Dawley rats, $\mathrm{Li}$ et al showed that this denervation resulted in a change in circadian clock gene expression. ${ }^{39}$ Per2 and Bmal1 mRNA and protein levels were both decreased while $\mathrm{AT}_{1} \mathrm{R}$ mRNA was upregulated in the SCN of SAD rats. Makino et al also noted that SAD rats lost rhythmicity of blood pressure. ${ }^{40}$ Given the neuronal connections between the carotid sinus and aortic arch to the NTS, these data again highlight the connection between the brain and circadian rhythms in maintaining proper control of blood pressure.

\section{Circadian blood pressure patterns in distinct subject populations Resistant hypertension}

Resistant hypertension occurs when a patient is on three or more antihypertensive medications, ideally one being a diuretic, and still has blood pressure levels which are not at goal. ${ }^{41}$ Patients with resistant hypertension have even higher risks of developing CVD. ${ }^{42}$ Diagnosis of resistant hypertension is not always clear cut, as the phenomenon of "white coat syndrome" can skew blood pressure readings. White coat syndrome refers to patients who have higher blood pressure readings in clinics than when they are resting at home, thus these patients have higher recorded blood pressure than what they normally experience. One way to get accurate blood pressure data without the confounding effects of white coat syndrome is to employ ambulatory blood pressure monitoring (ABPM). This allows for constant blood pressure monitoring for more accurate measurements which 
in turn leads to a more accurate correlation between blood pressure and CVD risk. ${ }^{43-45}$

In an extensive review, Hermida et $\mathrm{al}^{46}$ point out that due to white coat syndrome, many patients diagnosed with resistant hypertension may not actually be resistant to treatment. One study of over 3,000 patients found that over $17 \%$ of them had isolated-office hypertension, or high blood pressure at the doctor but controlled blood pressure at home measured by ABPM. ${ }^{47}$ Therefore, ABPM is a valuable tool to accurately diagnose patients with hypertension and to assess the control of the condition.

In an editorial, Kario suggests that melatonin may be a treatment for resistant hypertension. ${ }^{48}$ A $2.5-3 \mathrm{mg}$ dose of melatonin taken 1 hour before bed for 3 weeks lowers blood pressure in hypertensive patients. ${ }^{49,50}$ The melatonin agonist ramelteon decreased sleep latency in humans. ${ }^{51}$ A recent small study in type 2 diabetics with non-dipping hypertension demonstrated that melatonin treatment was significantly associated with correction of the dipping pattern and lowering of blood pressure. ${ }^{52}$ In vivo studies support a blood pressure-lowering role of melatonin, possibly due to increased nitric oxide production and central pathway involvement. ${ }^{53}$ The action of melatonin on the peripheral and central nervous system has recently been reviewed and postulated to be a possible treatment for hypertension. ${ }^{54}$

Arterial vasodilation is reduced in patients with resistant hypertension. ${ }^{55} \mathrm{~A}$ new division in patients with resistant hypertension has been made, separating them into patients with controlled resistant hypertension (controlled blood pressure with four or more antihypertensive medications) and patients with uncontrolled resistant hypertension. Quinaglia et al showed that these two groups of patients with resistant hypertension have different characteristics. ${ }^{56}$ The group with uncontrolled resistant hypertension exhibited greater endothelial function impairment and less of a night time dip in blood pressure. Even though calcium channel blockers, ACE inhibitors, and ARBs all promote nitric oxide release (which in turn helps preserve endothelial function $)^{57}$ these patients still exhibit damaged endothelium. Resistant hypertensive patients have higher levels of plasma aldosterone levels than other hypertensive patients which contribute to endothelial dysfunction. ${ }^{56}$ Since few patients were taking aldosterone antagonists, Quinaglia et al speculate that increased aldosterone levels could be the cause for the endothelial impairment observed in resistant hypertensive patients.

Heart rate variability (HRV) is used to assess autonomic nervous system function. ${ }^{58}$ Reduced HRV is a predictor of decreased cardiovascular prognosis in patients with hypertension. ${ }^{59}$ Decreased HRV is also associated with a higher risk of developing hypertension and being a non-dipper. ${ }^{60}$ Patients with resistant hypertension also have a high incidence of obstructive sleep apnea (OSA) ${ }^{61}$ and OSA is classified as a risk factor for resistant hypertension. ${ }^{42}$ Salles et al monitored over 400 patients with resistant hypertension via ABPM. ${ }^{60}$ They found that two reduced HRV parameters were correlated with a decreased night time dip in blood pressure. They also found that non-dippers had an increased prevalence of OSA compared to dippers.

\section{Sleep apnea}

It has been known for some time that myocardial infarction (MI) occurrence exhibits an apparent circadian pattern, ${ }^{62}$ peaking in early morning hours in conjunction with a rise in blood pressure and heart rate. OSA has been correlated with a higher risk of $\mathrm{MI}$ in the morning compared to patients without OSA. ${ }^{63}$ Nakashima et al studied 216 patients with OSA and found that patients with moderate to severe OSA had a higher incidence of MI between 6 am and noon compared to controls. ${ }^{64}$ This finding was consistent with previous studies. ${ }^{63,65}$

A correlation between OSA and hypertension has been demonstrated. ${ }^{66}$ Wang et al further examined the relationship between OSA and hypertension in over 3,000 patients ranging in age from 18-81 years old. ${ }^{67}$ They found that patients with OSA had a significantly higher incidence of hypertension compared to those without OSA and that severity of hypertension was positively correlated with severity of OSA. OSA patients have higher day and night time blood pressure with altered circadian rhythms of blood pressure. It has been shown previously that continuous positive airway pressure (CPAP) treatment effectively decreases day and nighttime blood pressure. ${ }^{68,69}$ Thus, the authors suggest that CPAP may be an effective treatment not only for OSA but also hypertension and altered circadian rhythms of blood pressure.

The HIPARCO trial investigated the effectiveness of CPAP treatment on patients with resistant hypertension and OSA. ${ }^{70}$ In a study of 194 patients whose blood pressure was monitored with 24 hour ABPM, the authors found that CPAP treatment not only decreased blood pressure in patients with resistant hypertension but also helped restore a nocturnal dipping pattern in blood pressure. They also found that there is a positive correlation with the duration of CPAP treatment and blood pressure reduction. It appears that CPAP treatment may be effective for patients with resistant hypertension to not only treat the commonly associated OSA but also to help 
restore the circadian pattern of dipping and therefore reduce the risk of CVD.

Kario et al investigated an alternative therapy for patients with hypertension and OSA using nocturnal administration of the antihypertensive medications nifedipine (a calcium channel blocker) and carvedilol (a $\beta / \alpha_{1}$ blocker). ${ }^{71}$ A blood pressure surge occurs after episodes of sleep apnea ${ }^{72}$ and this surge may be related to sleep-onset cardiovascular events such as wake-up strokes ${ }^{73}$ and $\mathrm{MI}^{74}$ in patients with OSA. Kario et al used a type of blood pressure monitoring device recently developed by their group. ${ }^{71}$ This trigger sleep blood pressure monitoring method measures blood pressure in fixed intervals as other ABPM devices but also measures blood pressure when oxygen levels fall below a certain threshold (as in an episode of sleep apnea). While both medications were found to reduce mean sleep blood pressure, nifedipine was found to lower mean and basal sleep systolic blood pressure (SBP) more than carvedilol and only carvedilol decreased the sleep SBP surge. The authors suggest this may be a valid alternative treatment for hypertension in OSA patients as CPAP patient compliance is low.

\section{Shift workers}

Mounting evidence ties disruptions in circadian rhythms with many disease states. Disruptions in circadian proteins as evidenced by mouse knockout models can lead to changes in blood pressure regulation and hypertension which in turn can lead to a number of diseases including CVD and ESRD. Shift work can lead to disrupted circadian rhythms with deleterious effects on health. A number of studies in different countries have looked at the effect of disrupted circadian rhythms of sleep in humans.

In Brazil, Pimenta et al examined 211 workers between 30-64 years of age on the health campus of a university. ${ }^{75}$ They found that these shift workers had a $67 \%$ increased cardiovascular risk compared to controls. In People's Republic of China, Guo et $\mathrm{al}^{76}$ studied over 26,000 retired workers, and found that even after retirement, shift workers still have worse sleep than non-shift working counterparts. ${ }^{77}$ The average age of the participants was about 64 years old and about $44 \%$ were males. The authors of this study found that even in retirement, shift workers had an increased risk of diabetes, hypertension, and poor sleep quality. Poor sleep quality was associated with short-term shift work of less than 10 years while hypertension and diabetes were associated with longterm shift work of greater than 10 years.

In the United States, black non-Hispanics have a greatly increased incidence of hypertension compared to white non-Hispanics. ${ }^{78}$ In order to investigate how shift work affects blacks, Lieu et al examined data from over 95,000 women participants of the Nurses' Health Study II. ${ }^{79}$ It was found that blacks who worked rotating night shifts had an increased risk of hypertension while there was no increased risk for whites.

While some studies have found a correlation between shift work and increased risk of hypertension, others have found no correlation. In a study looking at over 25,000 German car manufacturers 16-64 years old, Ohlander et al concluded that hypertension was lowest among people who did not work in shifts and highest in those who did not work night shifts. ${ }^{80}$ After the authors adjusted for behavioral factors, they report no increased risk of hypertension for any shift work category. A Finnish study looked at over 20,000 pairs of twins (the Finnish Twin Cohort) and found no correlation between shift work and increased risk of CVD or hypertension. ${ }^{81}$

There are many possible explanations for the differences seen in these analyses. The authors of the Finnish study note that there is a clear difference between male and female shift work, with males typically having well-earning jobs and female shift workers having less well-paying jobs. ${ }^{81}$ They also point out that there are geographic differences to be considered, such as the fact that cholesterol levels are lower in Japan than Western parts of the world. ${ }^{82}$ There are many other variables which may confound results including the large age ranges as it may be the case that certain ages are more susceptible to developing hypertension due to shift work. Also the very definition of shift work is unclear so the type of circadian disturbances experienced may vary depending on the type of jobs included in the analyses. For an extremely detailed and well-written review of shift work and possible consequences, see a review by Esquirol et al. ${ }^{83}$

\section{Clinical studies: importance of ABPM}

In a recently completed study, Toker et al examined the relationship between hypertensive parents and their children. ${ }^{84}$ They found that children with hypertensive parents or grandparents had significantly higher systolic burdens than control children. They also found that children with hypertensive parents or grandparents had significantly higher left ventricular posterior wall thickness than control subjects. Moreover, left ventricular mass was negatively associated with non-dipper status. Thus, the authors conclude that in children with a familial history of hypertension, target organ damage may occur before hypertension is even diagnosed. 
While ambulatory blood pressure has been shown to be a good way to assess risk of CVD and organ damage, Kanno et al demonstrated that it is also a good predictor of CKD development. ${ }^{85}$ The study used over 800 participants with an average age of 63 . They found that much like CVD and organ damage, there is an association of CKD with aberrant 24 hour blood pressure profiles, an observation made possible by the use of ABPM. Moreover, nighttime blood pressure was found to be the most accurate predictor of CKD progression.

Wei et al examined data from over 1,000 patients with a median age of about 50 years. ${ }^{86}$ The majority of these patients (about 90\%) had never been treated for hypertension and the ones who had been were untreated for at least 2 weeks. Using ABPM, they found that hypertensive patients had significantly higher left ventricular mass index values. They determined that 24 hour SBP and systolic and diastolic hypertension were significant predictors of organ damage.

As previously mentioned, different drugs of the same class may have different effects on blood pressure control due to the different properties of the drug. Kario et al designed a study to investigate the effectiveness of two different ARBs (azilsartan and amlodipine) on nocturnal blood pressure and blood pressure rhythms ${ }^{87}$ Participants will be divided into two groups of 350 people each, one receiving each drug. Measurements will be made using ABPM. This ACS1 study hopes to elucidate the possible different effects of two drugs in the ARB class and investigate whether one or the other is better at controlling nocturnal blood pressure and restoring circadian blood pressure rhythms.

While there seems to be numerous benefits to nighttime dosing of hypertension medication, possible risks have been suggested. Hayreh et al found that low nocturnal arterial blood pressure can lead to ocular vascular diseases such as ischemic optic neuropathy. ${ }^{88}$ This could be a potential problem for people who have a normal dipping pattern as nighttime dosing could lead to a further decrease in blood pressure, thus causing arterial hypotension. From a study of 88 patients, another group found evidence that nighttime dosing of hypertension medications again lead to hypotension which they correlated with increased optic nerve damage in patients with open-angle glaucoma. ${ }^{89}$ In order to determine effectiveness and risks of nighttime dosing versus traditional morning dosing of hypertension medications, Carter et al have proposed a study with patients taking hypertension medications in the morning or at night. ${ }^{90}$ They will follow patients for 36-42 months and attempt to determine if nighttime dosing reduces CVD risk compared to traditional morning dosing. They expect results to be available in 2018 .

\section{Implications for treatment of hypertension: chronotherapy}

An increasing number of studies consistently demonstrate that the time of day therapeutics are administered can have an effect on the effectiveness of the drug. Administering a drug at a specific time of day in order to improve its efficacy is referred to as chronotherapy. With respect to hypertension, it has been found that patients taking ACE inhibitors or ARBs at night had an increased drop in blood pressure compared to those patients taking the same medications in the morning. ${ }^{91,92}$ Specific medications and outcomes in distinct patient populations have been thoroughly reviewed by Hermida et al. ${ }^{693}$ In general, ACE inhibitors and ARBs seem to be more effective when taken at night. This effectiveness also includes an increase in dipping which is correlated with a decreased risk of CVD.

As previously mentioned, people are termed non-dippers if they do not experience the normal $10 \%-20 \%$ decrease in blood pressure at night. Non-dipping has been linked to increased risk of adverse cardiovascular events. ${ }^{94,95}$ The MAPEC study followed over 2,000 hypertensive patients over the course of a median of 5.6 years..$^{92,96}$ The study divided participants into two groups, one taking all blood pressure medications upon waking and the other group taking at least one medication at night. The nighttime dosing group showed significant reduction in sleep blood pressure and an increase in dipping of almost $30 \%$ compared to the morning dosing group. At the follow-up, the nighttime dosing group had a lower risk of cardiovascular events. They also exhibited significantly reduced morbidity and mortality due to CVD.

In a letter to the editor of Hypertension, Portaluppi et al highlighted the effectiveness of chronotherapy in the Heart Outcomes Prevention Evaluation (HOPE) trial and posited that evening administration of anti-hypertensive agents could explain the beneficial outcome of a substudy of HOPE. ${ }^{97}$ In the HOPE substudy, evening administration of the ACE inhibitor ramipril was associated with better lowering of night time blood pressure, decreased non-dipping profile, and these results were associated with reduced cardiovascular morbidity and mortality. ${ }^{98}$ These results demonstrate the beneficial effects of chronotherapy and also the use of ABPM.

\section{Summary}

While there is a need to improve current hypertension treatments, there are many emerging ideas with the promise of 
increasing treatment effectiveness. The concept of chronotherapy is a simple fix based on complex ongoing research. By taking the circadian timing of physiological processes such as drug metabolism and receptor expression into account, drugs can be more effective at the same doses simply by changing the time at which they are administered. Similarly, monitoring the circadian pattern of blood pressure can help to not only diagnose those people at a higher risk of having a cardiac event but also help indicate which type of treatment would be more effective, as in the case of people with true resistant hypertension. Since hypertension appears to be associated with other diseases such as OSA, it may also be helpful to target treatment to these other dysfunctions in order to treat both problems. Hypertension is intricately connected to many physiological functions and it should not be thought of as an isolated disease when determining treatment.

\section{Disclosure}

The authors have no conflicts of interest to disclose.

\section{References}

1. Richards J, Gumz ML. Advances in understanding the peripheral circadian clocks. FASEB J. 2012;26(9):3602-3613.

2. Richards J, Gumz ML. Invited Review EB 2012: Mechanism of the Circadian Clock in Physiology. Am J Physiol Regul Integr Comp Physiol. 2013;304(12):R1053-R1064.

3. Zhang R, Lahens NF, Ballance HI, Hughes ME, Hogenesch JB. A circadian gene expression atlas in mammals: implications for biology and medicine. Proc Natl Acad Sci U S A. 2014;111(45):16219-16224.

4. Mohawk JA, Green CB, Takahashi JS. Central and peripheral circadian clocks in mammals. Annu Rev Neurosci. 2012;35:445-462.

5. Zweiker R, Eber B, Schumacher M, Toplak H, Klein W. "Non-dipping" related to cardiovascular events in essential hypertensive patients. Acta Med Austriaca. 1994;21(3):86-89.

6. Hermida RC, Ayala DE, Smolensky MH, et al. Chronotherapy improves blood pressure control and reduces vascular risk in CKD. Nat Rev Nephrol. 2013;9(6):358-368.

7. Kario K, Shimada K. Risers and extreme-dippers of nocturnal blood pressure in hypertension: antihypertensive strategy for nocturnal blood pressure. Clin Exp Hypertens. 2004;26(2):177-189.

8. Fogari R, Zoppi A, Malamani GD, Lazzari P, Destro M, Corradi L. Ambulatory blood pressure monitoring in normotensive and hypertensive type 2 diabetes. Prevalence of impaired diurnal blood pressure patterns. Am J Hypertens. 1993;6(1):1-7.

9. Hermida RC, Ayala DE, Fernandez JR, Calvo C. Chronotherapy improves blood pressure control and reverts the nondipper pattern in patients with resistant hypertension. Hypertension. 2008;51(1):69-76.

10. Hyman DJ, Ogbonnaya K, Taylor AA, Ho K, Pavlik VN. Ethnic differences in nocturnal blood pressure decline in treated hypertensives. Am J Hypertens. 2000;13(8):884-891.

11. Rodriguez CJ, Jin Z, Schwartz JE, et al. Socioeconomic status, psychosocial factors, race and nocturnal blood pressure dipping in a Hispanic cohort. Am J Hypertens. 2013;26(5):673-682.

12. Kobori H, Nangaku M, Navar LG, Nishiyama A. The intrarenal reninangiotensin system: from physiology to the pathobiology of hypertension and kidney disease. Pharmacol Rev. 2007;59(3):251-287.

13. Go AS, Mozaffarian D, Roger VL, et al. Executive summary: heart disease and stroke statistics - 2014 update: a report from the American Heart Association. Circulation. 2014;129(3):399-410.
14. Hsu CY, McCulloch CE, Darbinian J, Go AS, Iribarren C. Elevated blood pressure and risk of end-stage renal disease in subjects without baseline kidney disease. Arch Intern Med. 2005;165(8):923-928.

15. Oparil S, Yarows SA, Patel S, Fang H, Zhang J, Satlin A. Efficacy and safety of combined use of aliskiren and valsartan in patients with hypertension: a randomised, double-blind trial. Lancet. 2007;370(9583): 221-229.

16. Giles TD, Alessi T, Purkayastha D, Zappe D. Comparative efficacy of aliskiren/valsartan vs valsartan in nocturnal dipper and nondipper hypertensive patients: a pooled analysis. J Clin Hypertens (Greenwich). 2012;14(5):299-306.

17. Baltatu OC, Campos LA, Bader M. Local renin-angiotensin system and the brain - a continuous quest for knowledge. Peptides. 2011;32(5): 1083-1086.

18. Diz DI, Arnold AC, Nautiyal M, Isa K, Shaltout HA, Tallant EA. Angiotensin peptides and central autonomic regulation. Curr Opin Pharmacol. 2011;11(2):131-137.

19. Campos LA, Bader M, Baltatu OC. Brain Renin-Angiotensin system in hypertension, cardiac hypertrophy, and heart failure. Front Physiol. 2011;2:115.

20. Baltatu O, Silva JA Jr, Ganten D, Bader M. The brain renin-angiotensin system modulates angiotensin II-induced hypertension and cardiac hypertrophy. Hypertension. 2000;35(1 Pt 2):409-412.

21. Baltatu O, Janssen BJ, Bricca G, et al. Alterations in blood pressure and heart rate variability in transgenic rats with low brain angiotensinogen. Hypertension. 2001;37(2 Pt 2):408-413.

22. Baltatu O, Campos LA, Bader M. Genetic targeting of the brain reninangiotensin system in transgenic rats: impact on stress-induced renin release. Acta Physiol Scand. 2004;181(4):579-584.

23. White WB. Ambulatory blood pressure monitoring: dippers compared with non-dippers. Blood Press Monit. 2000;5 Suppl 1:S17-S23.

24. Jensen LW, Pedersen EB. Nocturnal blood pressure and relation to vasoactive hormones and renal function in hypertension and chronic renal failure. Blood Press. 1997;6(6):332-342.

25. Richards J, Diaz AN, Gumz ML. Clock genes in hypertension: novel insights from rodent models. Blood Press Monit. 2014;19(5): $249-254$.

26. Doi M, Takahashi Y, Komatsu R, et al. Salt-sensitive hypertension in circadian clock-deficient Cry-null mice involves dysregulated adrenal Hsd3b6. Nat Med. 2010;16(1):67-74.

27. Sueta D, Koibuchi N, Hasegawa Y, et al. Blood pressure variability, impaired autonomic function and vascular senescence in aged spontaneously hypertensive rats are ameliorated by angiotensin blockade. Atherosclerosis. 2014;236(1):101-107.

28. Michel MC, Foster C, Brunner HR, Liu L. A systematic comparison of the properties of clinically used angiotensin II type 1 receptor antagonists. Pharmacol Rev. 2013;65(2):809-848.

29. Takai S, Jin D, Ikeda H, Sakonjo H, Miyazaki M. Significance of angiotensin II receptor blockers with high affinity to angiotensin II type 1 receptors for vascular protection in rats. Hypertens Res. 2009;32(10): $853-860$.

30. Cowley AW Jr. Renal medullary oxidative stress, pressure-natriuresis, and hypertension. Hypertension. 2008;52(5):777-786.

31. Svetkey LP, McKeown SP, Wilson AF. Heritability of salt sensitivity in black Americans. Hypertension. 1996;28(5):854-858.

32. Cowley AW Jr, Moreno C, Jacob HJ, et al. Characterization of biological pathways associated with a $1.37 \mathrm{Mbp}$ genomic region protective of hypertension in Dahl S rats. Physiol Genomics. 2014;46(11): 398-410.

33. Takano A, Isojima Y, Nagai K. Identification of mPer1 phosphorylation sites responsible for the nuclear entry. J Biol Chem. 2004;279(31): 32578-32585.

34. Reischl S, Vanselow K, Westermark PO, et al. Beta-TrCP1-mediated degradation of PERIOD2 is essential for circadian dynamics. $J$ Biol Rhythms. 2007;22(5):375-386.

35. Buijs RM, Kalsbeek A. Hypothalamic integration of central and peripheral clocks. Nat Rev Neurosci. 2001;2(7):521-526. 
36. Peters RV, Zoeller RT, Hennessey AC, Stopa EG, Anderson G, Albers HE. The control of circadian rhythms and the levels of vasoactive intestinal peptide mRNA in the suprachiasmatic nucleus are altered in spontaneously hypertensive rats. Brain Res. 1994;639(2):217-227.

37. Goncharuk VD, van Heerikhuize J, Dai JP, Swaab DF, Buijs RM. Neuropeptide changes in the suprachiasmatic nucleus in primary hypertension indicate functional impairment of the biological clock. J Comp Neurol. 2001;431(3):320-330.

38. Buijs FN, Cazarez F, Basualdo MC, et al. The suprachiasmatic nucleus is part of a neural feedback circuit adapting blood pressure response. Neuroscience. 2014;266:197-207.

39. Li H, Sun NL, Wang J, Liu AJ, Su DF. Circadian expression of clock genes and angiotensin II type 1 receptors in suprachiasmatic nuclei of sinoaortic-denervated rats. Acta Pharmacol Sin. 2007;28(4): 484-492.

40. Makino M, Hayashi H, Takezawa H, Hirai M, Saito H, Ebihara S. Circadian rhythms of cardiovascular functions are modulated by the baroreflex and the autonomic nervous system in the rat. Circulation. 1997;96(5):1667-1674.

41. Fagard RH. Resistant hypertension. Heart. 2012;98(3):254-261.

42. Calhoun DA, Jones D, Textor S, et al. Resistant hypertension: diagnosis, evaluation, and treatment: a scientific statement from the American Heart Association Professional Education Committee of the Council for High Blood Pressure Research. Circulation. 2008;117(25):e510-e526.

43. Salles GF, Cardoso CR, Muxfeldt ES. Prognostic influence of office and ambulatory blood pressures in resistant hypertension. Arc Intern Med. 2008;168(21):2340-2346.

44. Redon J, Campos C, Narciso ML, Rodicio JL, Pascual JM, Ruilope LM. Prognostic value of ambulatory blood pressure monitoring in refractory hypertension: a prospective study. Hypertension. 1998;31(2): $712-718$.

45. Clement DL, De Buyzere ML, De Bacquer DA, et al. Prognostic value of ambulatory blood-pressure recordings in patients with treated hypertension. N Engl J Med. 2003;348(24):2407-2415.

46. Hermida RC, Ayala DE, Rios MT, Fernandez JR, Mojon A, and Smolensky MH. Around-the-clock ambulatory blood pressure monitoring is required to properly diagnose resistant hypertension and assess associated vascular risk. Curr hypertens rep. 2014;16(7):445.

47. Rios MT, Dominguez-Sardina M, Ayala DE, et al. Prevalence and clinical characteristics of isolated-office and true resistant hypertension determined by ambulatory blood pressure monitoring. Chronobiol Int. 2013;30(1-2):207-220.

48. Kario K. Are melatonin and its receptor agonist specific antihypertensive modulators of resistant hypertension caused by disrupted circadian rhythm? J Am Soc Hypertens. 2011;5(5):354-358.

49. Scheer FA, Van Montfrans GA, van Someren EJ, Mairuhu G, Buijs RM. Daily nighttime melatonin reduces blood pressure in male patients with essential hypertension. Hypertension. 2004;43(2):192-197.

50. Cagnacci A, Cannoletta M, Renzi A, Baldassari F, Arangino S, Volpe A. Prolonged melatonin administration decreases nocturnal blood pressure in women. Am J Hypertens. 2005;18(12 Pt 1):1614-1618.

51. Miyamoto M. Pharmacology of ramelteon, a selective MT1/MT2 receptor agonist: a novel therapeutic drug for sleep disorders. CNS Neurosci Ther. 2009; 15(1):32-51.

52. Mozdzan M, Mozdzan M, Chalubinski M, Wojdan K, Broncel M. The effect of melatonin on circadian blood pressure in patients with type 2 diabetes and essential hypertension. Arch Med Sci. 2014;10(4): 669-675.

53. Paulis L, Simko F. Blood pressure modulation and cardiovascular protection by melatonin: potential mechanisms behind. Physiol Res. 2007;56(6):671-684.

54. Pechanova O, Paulis L, Simko F. Peripheral and central effects of melatonin on blood pressure regulation. Int J Mol Sci. 2014;15(10): 17920-17937.

55. Yugar-Toledo JC, Tanus-Santos JE, Sabha M, et al. Uncontrolled hypertension, uncompensated type II diabetes, and smoking have different patterns of vascular dysfunction. Chest. 2004;125(3):823-830.
56. Quinaglia T, Martins LC, Figueiredo VN, et al. Non-dipping pattern relates to endothelial dysfunction in patients with uncontrolled resistant hypertension. J Hum Hypertens. 2011;25(11):656-664.

57. Taddei S, Virdis A, Ghiadoni L, Sudano I, Salvetti A. Effects of antihypertensive drugs on endothelial dysfunction: clinical implications. Drugs. 2002;62(2):265-284.

58. Xhyheri B, Manfrini O, Mazzolini M, Pizzi C, Bugiardini R. Heart rate variability today. Prog Cardiovasc Dis. 2012;55(3):321-331.

59. Gerritsen J, Dekker JM, TenVoorde BJ, et al. Impaired autonomic function is associated with increased mortality, especially in subjects with diabetes, hypertension, or a history of cardiovascular disease: the Hoorn Study. Diabetes Care. 2001;24(10):1793-1798.

60. Salles GF, Ribeiro FM, Guimaraes GM, Muxfeldt ES, Cardoso CR. A reduced heart rate variability is independently associated with a blunted nocturnal blood pressure fall in patients with resistant hypertension. J Hypertens. 2014;32(3):644-651.

61. Pedrosa RP, Drager LF, Gonzaga CC, et al. Obstructive sleep apnea: the most common secondary cause of hypertension associated with resistant hypertension. Hypertension. 2011;58(5):811-817.

62. Muller JE, Stone PH, Turi ZG, et al. Circadian variation in the frequency of onset of acute myocardial infarction. $N$ Engl J Med. 1985;313(21): $1315-1322$

63. Aboyans V, Cassat C, Lacroix P, et al. Is the morning peak of acute myocardial infarction's onset due to sleep-related breathing disorders? A prospective study. Cardiology. 2000;94(3):188-192.

64. Nakashima H, Henmi T, Minami K, et al. Obstructive sleep apnoea increases the incidence of morning peak of onset in acute myocardial infarction. Eur Heart J Acute Cardiovasc Care. 2013;2(2):153-158.

65. Junker-Neff A, Eberle R, T VA, Mehilli J, Hollweck R. Besteht ein Zusammenhang zwischen dem Schlafapnoesyndrom und der zirkadianen Häufung von Myokardinfarkten in den Morgenstunden? [Is there an association between the sleep apnea syndrome and the circadian peak of myocardial infarction in the morning hours?]. Dtsch Med Wochenschr. 2005;130(49):2818-2822. German.

66. Nieto FJ, Young TB, Lind BK, et al. Association of sleep-disordered breathing, sleep apnea, and hypertension in a large community-based study. Sleep Heart Health Study. JAMA. 2000;283(14):1829-1836.

67. Wang Y, Li C, Feng L, Feng J, Cao J, Chen B. Prevalence of hypertension and circadian blood pressure variations in patients with obstructive sleep apnoea-hypopnoea syndrome. J Int Med Res. 2014;42(3): 773-780.

68. Litvin AY, Sukmarova ZN, Elfimova EM, et al. Effects of CPAP on "vascular" risk factors in patients with obstructive sleep apnea and arterial hypertension. Vasc Health Risk Manag. 2013;9:229-235.

69. Yorgun H, Kabakci G, Canpolat U, et al. Predictors of blood pressure reduction with nocturnal continuous positive airway pressure therapy in patients with obstructive sleep apnea and prehypertension. Angiology. 2014;65(2):98-103.

70. Martinez-Garcia MA, Capote F, Campos-Rodriguez F, et al. Effect of CPAP on blood pressure in patients with obstructive sleep apnea and resistant hypertension: the HIPARCO randomized clinical trial. JAMA. 2013;310(22):2407-2415

71. Kario K, Kuwabara M, Hoshide S, Nagai M, Shimpo M. Effects of nighttime single-dose administration of vasodilating vs sympatholytic antihypertensive agents on sleep blood pressure in hypertensive patients with sleep apnea syndrome. J Clin Hypertens (Greenwich). 2014;16(6): 459-466.

72. Planes C, Leroy M, Fayet G, Aegerter P, Foucher A, Raffestin B. Exacerbation of sleep-apnoea related nocturnal blood-pressure fluctuations in hypertensive subjects. Eur Respir J. 2002;20(1):151-157.

73. Hsieh SW, Lai CL, Liu CK, Hsieh CF, Hsu CY. Obstructive sleep apnea linked to wake-up strokes. J Neurol. 2012;259(7):1433-1439.

74. Kuniyoshi FH, Garcia-Touchard A, Gami AS, et al. Day-night variation of acute myocardial infarction in obstructive sleep apnea. $J$ Am Coll Cardiol. 2008;52(5):343-346.

75. Pimenta AM, Kac G, Souza RR, Ferreira LM, Silqueira SM. Night-shift work and cardiovascular risk among employees of a public university. Rev Assoc Med Bras. 2012;58(2):168-177. 
76. Guo Y, Liu Y, Huang X, Rong Y, He M, Wang Y, et al. The effects of shift work on sleeping quality, hypertension and diabetes in retired workers. PLoS One. 2013;8(8):e71107.

77. Monk TH, Buysse DJ, Billy BD, et al. Shiftworkers report worse sleep than day workers, even in retirement. J Sleep Res. 2013;22(2): 201-208.

78. Ong KL, Cheung BM, Man YB, Lau CP, Lam KS. Prevalence, awareness, treatment, and control of hypertension among United States adults 1999-2004. Hypertension. 2007;49(1):69-75.

79. Lieu SJ, Curhan GC, Schernhammer ES, Forman JP. Rotating night shift work and disparate hypertension risk in African-Americans. J Hypertens. 2012;30(1):61-66.

80. Ohlander J, Keskin MC, Stork J, Radon K. 0170 Shift work and hypertension: prevalence and analysis of disease pathways in German car manufacturing workers. Occup Environ Med. 2014;71 Suppl 1:A81.

81. Hublin C, Partinen M, Koskenvuo K, Silventoinen K, Koskenvuo M, Kaprio J. Shift-work and cardiovascular disease: a population-based 22-year follow-up study. Eur J Epidemiol. 2010;25(5):315-323.

82. Ueshima H. Explanation for the Japanese paradox: prevention of increase in coronary heart disease and reduction in stroke. JAtheroscler Thromb. 2007;14(6):278-286.

83. Esquirol Y, Perret B, Ruidavets JB, et al. Shift work and cardiovascular risk factors: new knowledge from the past decade. Arch Cardiovasc Dis. 2011;104(12):636-668.

84. Toker RT, Yildirim A, Demir T, Ucar B, Kilic Z. Circadian blood pressure rhythm in normotensive offspring of hypertensive parents. Cardiol $J$. Epub July 8, 2014.

85. Kanno A, Kikuya M, Asayama K, et al. Night-time blood pressure is associated with the development of chronic kidney disease in a general population: the Ohasama Study. J Hypertens. 2013;31(12): 2410-2417.

86. Wei FF, Li Y, Zhang L, et al. Association of target organ damage with 24-hour systolic and diastolic blood pressure levels and hypertension subtypes in untreated Chinese. Hypertension. 2014;63(2):222-228.

87. Kario K, Hoshide S. Rationale, study design, and implementation of the ACS1 study: effect of azilsartan on circadian and sleep blood pressure as compared with amlodipine. Blood Press Monit. 2014;19(3):123-128.
88. Hayreh SS, Podhajsky P, Zimmerman MB. Role of nocturnal arterial hypotension in optic nerve head ischemic disorders. Ophthalmologica. 1999;213(2):76-96.

89. Krasinska B, Karolczak-Kulesza M, Krasinski Z, et al. Effects of the time of antihypertensive drugs administration on the stage of primary open-angle glaucoma in patients with arterial hypertension. Blood Press. 2012;21(4):240-248.

90. Carter BL, Chrischilles EA, Rosenthal G, Gryzlak BM, Eisenstein EL, Vander Weg MW. Efficacy and safety of nighttime dosing of antihypertensives: review of the literature and design of a pragmatic clinical trial. J Clin Hypertens (Greenwich). 2014;16(2):115-121.

91. Hermida RC, Ayala DE, Calvo C, Portaluppi F, Smolensky MH. Chronotherapy of hypertension: administration-time-dependent effects of treatment on the circadian pattern of blood pressure. Adv Drug Deliv Rev. 2007;59(9-10):923-939.

92. Hermida RC, Ayala DE, Mojon A, Fernandez JR. Influence of circadian time of hypertension treatment on cardiovascular risk: results of the MAPEC study. Chronobiol Int. 2010;27(8):1629-1651.

93. Hermida RC, Ayala DE, Fernandez JR, Portaluppi F, Fabbian F, Smolensky MH. Circadian rhythms in blood pressure regulation and optimization of hypertension treatment with ACE inhibitor and ARB medications. Am J Hypertens. 2011;24(4):383-391.

94. Routledge FS, McFetridge-Durdle JA, Dean CR; Canadian Hypertension Society. Night-time blood pressure patterns and target organ damage: a review. Can J Cardiol. 2007;23(2):132-138.

95. Hermida RC, Ayala DE, Portaluppi F. Circadian variation of blood pressure: The basis for the chronotherapy of hypertension. Adv Drug Deliv Rev. 2007;59(9-10):904-922.

96. Hermida RC, Ayala DE, Mojon A, Fernandez JR. Decreasing sleeptime blood pressure determined by ambulatory monitoring reduces cardiovascular risk. J Am Coll Cardiol. 2011;58(11):1165-1173.

97. Portaluppi F, Smolensky M, Ayala DE, Hermida RC. Nondipping and cardiovascular risk after morning renin-angiotensin blockade. Hypertension. 2013;61(2):e15.

98. Svensson P, de Faire U, Sleight P, Yusuf S, Ostergren J. Comparative effects of ramipril on ambulatory and office blood pressures: a HOPE Substudy. Hypertension. 2001;38(6):E28-E32.
ChronoPhysiology and Therapy

\section{Publish your work in this journal}

ChronoPhysiology and Therapy is an international, peer-reviewed open access journal focusing on research into the cyclic variations and rhythmicity in physiological processes in the body and the research and development and optimal timing of administration of therapeutic targets to achieve improved outcomes and quality of life for the patient. The

\section{Dovepress}

manuscript management system is completely online and includes a very quick and fair peer-review system. Visit http://www.dovepress.com/ testimonials.php to read real quotes from published authors. 